\title{
The Effect of Nutrition Education on Bone Health and Dietary Calcium Intake in Adolescent Girls with Chronic Lymphocytic Thyroiditis
}

\author{
Nevra Koç, Ph.D. ${ }^{1}$, Emine Akal Yıldız, Ph.D. ${ }^{2}$, Ihsan Esen, MD $^{3}$, Gülhan Samur, Ph.D. ${ }^{4}$ \\ Seyit Ahmet Uçaktürk, MD5 ${ }^{5}$ Mehmet Gündüz, MD $^{6}$ \\ ${ }^{1}$ Doctor Dietitian, Division of Nutrition and Dietetics, University of Health Sciences, Ankara Children's Health \\ and Diseases, Hematology-Oncology Training and Research Hospital. \\ ${ }^{2}$ Assoc. Prof, East Mediterranean University, Faculty of Health Sciences, Department of Nutrition and Dietetics. \\ ${ }^{3}$ Assoc Prof. Division of Pediatric Endocrinology, Medical School of Firat University, Department of Pediatrics. \\ ${ }^{4}$ Professor, Hacettepe University, Faculty of Health Sciences, Department of Nutrition and Dietetics. \\ ${ }^{5}$ Assoc. Prof, Division of Pediatric Endocrinology, University of Health Sciences, Ankara Children's Health and \\ Diseases, Hematology-Oncology Training and Research Hospital. \\ ${ }^{6}$ Assoc. Prof, Division of Pediatric Nutrition and Metabolism, University of Health Sciences, Ankara Children's \\ Health and Diseases, Hematology-Oncology Training and Research Hospital. \\ nevrakoc@yahoo.com
}

\section{Abstract}

Aim: The aim of our study is to evaluate adolescent girls with chronic lymphocytic thyroiditis (CLT), regarding eating habits, dietary calcium intake, anthropometric measurements, biochemical findings, bone mineral density (BMD) and to evaluate the effect of nutritional education on these parameters.

Material and Methods: Adolescent girls with CLT that were treated in our hospital were included. A matching group of healthy adolescent girls were also evaluated as a control group. Nutritional education was given at the beginning of study and every month during the study period. Anthrophometric measurements, biochemical findings and BMD were evaluated at the beginning of the study and after six months. The effect of nutritional recommendation was also evaluated.

Results: At the beginning of the study; adolescent girls with chronic lymphocytic thyroiditis had a dietary calcium intake about $54.4 \%(701 \pm 233 \mathrm{mg} /$ day $)$. It was shown that they reached a dietary calcium intake about $78.3 \%$ (1017 $\pm 212 \mathrm{mg} /$ day) after six months from the beginning of nutritional education $(\mathrm{p}<0.001)$. Positive correlations were found between dietary calcium intakes and BMD-z score $(p=0.037, r=0.376)$.

Conclusions: This study supported the idea that nutritional education and calcium intake might have positive effects on the BMD in the girls with chronic lymphocytic thyroiditis.

Keywords: Bone mineral density, Children, Chronic lymphocytic thyroiditis, Dietary calcium intake, nutrition education

\section{INTRODUCTION}

Chronic lymphocytic thyroiditis (CLT) is an autoimmune disorder frequently seen among adolescent girls. Levothyroxine therapy is given to these patients with overt hypothyroidism or to the patients who have subclinical hypothyroidism with or without goiter (1). Tri-iodothyronine (T3), regulates intramembranous and endocondral mineralization of bones and controls lineer growth and bone maturation by their effects on $\mathrm{TR} \alpha$ receptors on chondrocytes and osteoblasts (2). It is believed that subclinical hyperthyroidism along with levothyroxine therapy can negatively affect BMD. On the other hand, low thyroid stimulating hormone levels 
The Effect of Nutrition Education on Bone Health and Dietary Calcium Intake in Adolescent Girls with Chronic Lymphocytic Thyroiditis

was shown to be related with diminished skeletal construction (1). Clinical and subclinical hyperthyroidism is reported to be related to bone fracture risk. In a recent study, subclinical hyperthyroidism was reported to be associated with an increased risk of hip and other fractures, particularly among those with low TSH levels (3-5).

Although, some studies have shown the negative impacts of long-term levothroxin therapyon BMD, results of the clinical studies about this topic are controversial, especially in adolescent age group $(6,7)$.

Calcium (Ca) plays a key structural role as a component of hydroxyapatite. Dietary requirements for Ca varies according to the needs for bone development and maintenance, with greater needs during the periods of rapid growth in childhood and adolescence. In later years inadequate dietary Ca accelerates bone loss and may contribute to osteoporosis. However, it is unclear whether Ca supplementation in this period leads to optimization of BMD. Ca supplementation of the usual diet in post-menopausal women and older men has been shown to reduce the rate of loss of BMD. We have hypothesized that a diet rich in Ca can help decreasing the negative effect of thyroid hormone replacement on BMD for patients with hypothyroidism and planned to increase dietary Ca intake of these patients by means of nutritional education (8).

To our knowledge, there is no study investigating the effect of nutritional education on BMD in patients with chronic lymphocytic thyroiditis receiving levothyroxine treatment. The aim of this study was to investigate the nutritional advice about calcium-rich diet on BMD in adolescent girls with chronic lymphocytic thyroiditis.

\section{MATERIALS AND METHOD}

The study protocol was approved by the local ethic committee of. [Removed for blind peer review]

\section{Patients}

This study was conducted in the period between September 2010 and June 2012 in [Removed for blind peer review] on 31 adolescent girls, receiving levothyroxine therapy for the chronic lymphocytic thyroiditis, with the average age of $15.2 \pm 1.8(12.0-17.8)$ years. The initial dose of levothyroxine was $1-2 \mathrm{mcg} / \mathrm{kg} / \mathrm{day}$ then the continual adjustment of dose has been performed based on the patients' thyroid function tests to maintain euthyroidism. In addition, 30 healthy adolescent girls with no systemic disease and with an average age of $15.2 \pm 1.8(12.3-17.6)$ years were included as a control group. Diagnosis of CLT had been made by elevated antithyroid peroxidase antibodies (TPOAb) and/or antithyroglobulin antibodies (TgAb) as well as typical hypoechogenicity of the thyroid in high-resolution ultrasonography.

Female patients between 12-18 years of age, with a Tanner stage IV-V and within postmenarcarchal period and having levothyroxine treatment for at least 2 years with a diagnosis of CLT were included in the study. Patients who have Ca and/or vitamin D supplementation or who have vitamin D deficiency were not included in the study. Patients with other chronic diseases were also excluded.

At the beginning of the study, anthropometric measurements, laboratory tests, bone mineral densityand food consumption were evaluated. The study group was seen monthly for 6 months to be trained about calciumrich diet principles. The possible effect of dietary advices was assessed by re-performing the above-mentioned evaluations at the end of the study.

\section{Anthropometric Analysis}

Body weight was measured without shoes in light indoor clothing using SC-105 model electronic body scale from Bari-Med which was precise to $0.1 \mathrm{~kg}$. Height was measured to the nearest $0.1 \mathrm{~cm}$ using Stadiometer Model S100 height rod from Ayrton. Stature was measured from the highest point on the head when subject is standing in erect posture with head in Frankfurt horizontal plane. Body mass index (BMI) is formulated as weight $(\mathrm{kg}) /$ height $\left(\mathrm{m}^{2}\right)$. Weight standard deviation score (SDS), height-SDS and BMI-SDS were calculated for each subjects.

American Research Journal of Pediatrics

Page 2 
The Effect of Nutrition Education on Bone Health and Dietary Calcium Intake in Adolescent Girls with Chronic Lymphocytic Thyroiditis

\section{Biochemical Analysis}

All the laboratory measurements were conducted at the laboratory of [Removed for blind peer review] Hospital. Blood and urine samples were obtained in the morning, minimumafter 12 hours of midnight fasting. Serum calcium (Ca), phosphorus (P) and parathormone levels (PTH), alkaline phosphatase (ALP) activity and urinary calcium/creatinine $(\mathrm{Ca} / \mathrm{Crea})$ ratio were determined. Serum $25(\mathrm{OH})$ vitamin D [25(OH)D] was analysed by high performance liquid chromatography.

\section{BMD}

Bone mineral density was measured by Dual Energy X-Ray Absorptiometry (DEXA) in the spine lumbar area L1-L4 (Bone density measurements were performed with a Hologic QDR-4500A S/N 45130 bone densitometer (Hologic Inc., Bedford, MA, USA)). BMD z-score for age and gender was determined using the reference values for Turkish children (9).

\section{Food Analysis}

Energy and nutrient intake data was collected by 3-days dietary record, with one day being a weekend day, and was calculated by using BEBIS 7.0 version(Ebispro for Windows, Stuttgart, Germany; Turkish Version(BeBİ 7), Pasifik Dayanıklı Company (www.bebis.com.tr); Istanbul, 2017) (10).

The percentage of children meeting recommended dietary allowances for energy and nutrients was calculated based on "Dietary Guidelines for Turkey". Dietary calcium requirements are average $1300 \pm 20 \% \mathrm{mg} /$ day for adolescent girls. Four portion/a day dairy foods intake was considered to meet dietary reference calcium intake with this age groups (11).

All subjects, enrolled in the study, initially were questioned about their eating habits to identify the group. The patient group was given verbal instructions about calcium-rich diet, and performance of education was evaluated with 3-day food record in every follow up visit each month. Dietary Guidelines for Turkey was used as visual material during training (11). The patient group was monitored during six months with their 3-day food record, and positive behaviors were supported and the training was repeated. Also, some advices on negative eating habits were provided.

The study protocol was approved by the local ethic committee of [Removed for blind peer review] Training and Research Hospital. Written informed consent from all the subjects and parents was obtained.

\section{Statistical Analysis}

Statistical analysis was performed using the SPSS version 17.0 statistics package program (SPSS Inc UK Ltd., UK) Numerical data were expressed as mean \pm standard deviation. If displayed normal distribution, "Repeated Measures Analysis of Variance" was used for within- and between-group comparisons over time. "Paired T" test and "Independent T" test were performed in the case of significant interaction. "Wilcoxon test" and "Mann Whitney-U Test" were used, respectively, to examine within-group and between-group variables over time for data without a normal distribution. Correlations between variables were calculated using "Pearson's Correlation Analysis" for numerical data. Group differences or correlations with $p<0.05$ were considered to be statistically significant.

\section{RESULTS}

\section{Anthropometric and Biochemical Findings}

There was no difference between weight-SDS, height-SDS, and BMI-SDS, Ca, P, ALP, PTH, 25(OH)D levels, urinary $\mathrm{Ca} /$ Crea ratio, age-matched BMD z-scores and daily calcium intake at the beginning of the study of the groups. 
The Effect of Nutrition Education on Bone Health and Dietary Calcium Intake in Adolescent Girls with Chronic Lymphocytic Thyroiditis

There was no difference between the two groups regarding serum Ca, P, ALP, PTH, 25(OH)D levels, at the end of the study $(p>0.05)$ (Table 1). BMD z-score showed an increasing trend in the 31 adolescent girls with chronic lymphocytic thyroiditis $(\mathrm{p}=0.05)$. However, in the control group, BMD z-scores showed a trend to decrease, but this difference was not statistically significant $(p>0.05)$ (Table 2).

\begin{tabular}{|c|c|c|c|}
\hline \multirow[t]{2}{*}{ Measurements } & At beginning & After six months & \multirow[b]{2}{*}{$\mathbf{P}_{2}$} \\
\hline & Mean \pm SD & Mean \pm SD & \\
\hline \multicolumn{4}{|l|}{ Weight (kg) } \\
\hline Study & $52.87 \pm 7.75$ & $53.66 \pm 7.25$ & 0.673 \\
\hline Control & $53.43 \pm 9.00$ & $54.01 \pm 8.52$ & 0.673 \\
\hline $\mathrm{p}_{1}$ & 0.827 & 0.827 & \\
\hline \multicolumn{4}{|l|}{ Height (cm) } \\
\hline Study & $159.30 \pm 6.16$ & $160.49 \pm 5.55$ & 0.056 \\
\hline Control & $159.37 \pm 6.43$ & $159.95 \pm 6.39$ & 0.056 \\
\hline $\mathrm{p}_{1}$ & 0.880 & 0.880 & \\
\hline \multicolumn{4}{|l|}{ BMI $\left(\mathrm{kg} / \mathrm{m}^{2}\right)$} \\
\hline Study & $20.86 \pm 2.59$ & $20.92 \pm 2.37$ & 0.698 \\
\hline Control & $21.20 \pm 3.17$ & $21.13 \pm 2.84$ & 0.698 \\
\hline $\mathrm{p}_{1}$ & 0.695 & 0.695 & \\
\hline \multicolumn{4}{|l|}{ Calcium (mg/dl) } \\
\hline Study & $9.81 \pm 0.37$ & $9.75 \pm 0.48$ & 0.077 \\
\hline Control & $10.03 \pm 0.47$ & $9.73 \pm 0.68$ & 0.077 \\
\hline $\mathrm{p}_{1}$ & 0.400 & 0.400 & \\
\hline \multicolumn{4}{|l|}{ Phosphorus(mg/dl) } \\
\hline Study & $4.19 \pm 0.67$ & $4.12 \pm 0.55$ & 0.169 \\
\hline Control & $3.88 \pm 0.74$ & $3.98 \pm 0.53$ & 0.169 \\
\hline $\mathrm{p}_{1}$ & 0.139 & 0.139 & \\
\hline \multicolumn{4}{|c|}{ Alkalen phosphatase(U/L) } \\
\hline Study & $323.45 \pm 178.44$ & $310.01 \pm 165.44$ & 0.580 \\
\hline Control & $209.30 \pm 151.26$ & $199.25 \pm 140.36$ & 0.580 \\
\hline $\mathrm{p}_{1}$ & 0.643 & 0.643 & \\
\hline \multicolumn{4}{|c|}{ Parathormon $(\mathrm{pg} / \mathrm{ml})$} \\
\hline Study & $49.12 \pm 16.44$ & $48.96 \pm 21.14$ & 0.929 \\
\hline Control & $49.91 \pm 20.22$ & $49.50 \pm 18.35$ & 0.929 \\
\hline $\mathrm{p}_{1}$ & 0.888 & 0.888 & \\
\hline \multicolumn{4}{|l|}{ Vitamin D (ng/ml) } \\
\hline Study & $14.62 \pm 8.91$ & $14.17 \pm 7.40$ & 0.962 \\
\hline Control & $13.46 \pm 7.84$ & $13.04 \pm 6.04$ & 0.619 \\
\hline $\mathrm{p}_{1}$ & 0.773 & 0.629 & \\
\hline \multicolumn{4}{|c|}{ Urinary $\mathrm{Ca} /$ creatinin } \\
\hline Study & $0.07 \pm 0.12$ & $0.04 \pm 0.03$ & 0.523 \\
\hline Control & $0.03 \pm 0.03$ & $0.03 \pm 0.04$ & 0.920 \\
\hline $\mathrm{p}_{1}$ & 0.248 & 0.293 & \\
\hline
\end{tabular}


The Effect of Nutrition Education on Bone Health and Dietary Calcium Intake in Adolescent Girls with Chronic Lymphocytic Thyroiditis

\begin{tabular}{|c|c|c|c|}
\hline \multirow[t]{2}{*}{ Measurements } & At beginning & After six months & \multirow[b]{2}{*}{$\mathbf{P}_{2}$} \\
\hline & Mean \pm SD & Mean \pm SD & \\
\hline \multicolumn{4}{|l|}{ BMD Z-SCORE } \\
\hline Study & $-0.12 \pm 1,19$ & $-0.08 \pm 1,25$ & 0.546 \\
\hline Control & $-0.28 \pm 0,99$ & $-0.24 \pm 0,90$ & 0.325 \\
\hline $\mathrm{p}_{1}$ & 0.332 & 0.251 & \\
\hline \multicolumn{4}{|c|}{ Daily calcium intake } \\
\hline Study & $707 \pm 233$ & $1017 \pm 212$ & $<0.001$ \\
\hline Control & $690 \pm 189$ & $700 \pm 187$ & 0.544 \\
\hline $\mathrm{p}_{1}$ & 0.757 & $<0.001$ & \\
\hline
\end{tabular}

\section{Dietary Calcium Intake and BMD}

Dietary daily calcium intake of the study group significantly increased after six months follow up. While they were meeting 54.4\% (21.7-83.8) of their daily requirements at the beginning of the study, this percentage reached to $78.3 \%(54.0-127.0)$ at the last follow-up visits $(\mathrm{p}<0.001)$. Ca intake had significantly increased in the educated study group $(\mathrm{p}<0.001)$ but serum Ca levels were not different $(\mathrm{p}>0.05)$. In both groups, serum Ca levels were in the normal ranges as baseline values. At the end of the study, a positive correlation was determined between dietary calcium intake and BMD during follow up period only in the study group ( $\mathrm{P}=0.023)$. Similarly, BMD z-scores was positively correlated with dietary calcium intake ( $\mathrm{r}: 0.376 \mathrm{p}=0.037)$ in the study group (Figure. 1 ).

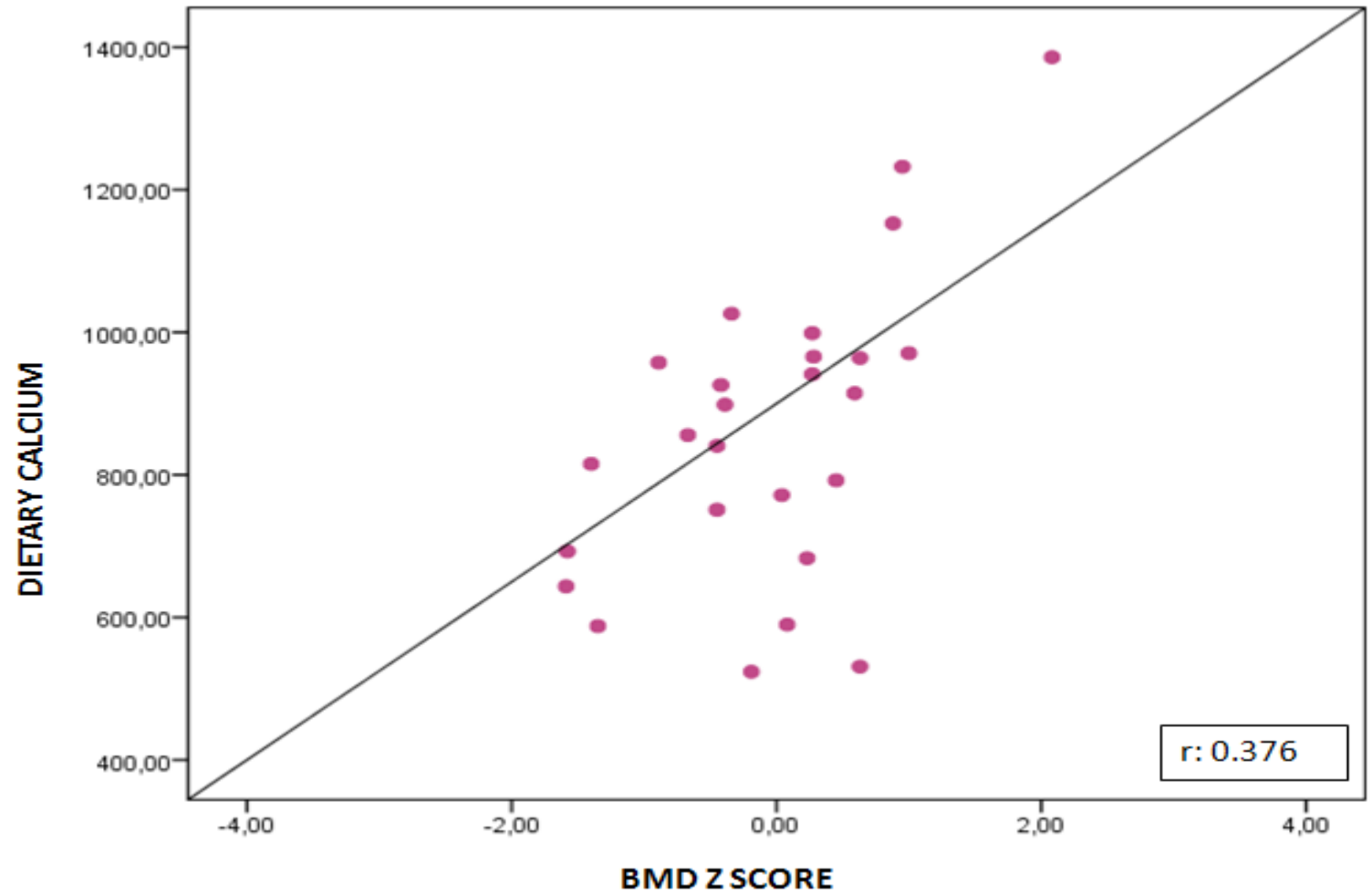

Fig1. Correlation's graphs of dietary calcium intake and BMD Z score 
The Effect of Nutrition Education on Bone Health and Dietary Calcium Intake in Adolescent Girls with Chronic Lymphocytic Thyroiditis

\section{DiscUSSION}

Calcium is required for normal growth, development and maintenance of the skeleton, where it provides strength and structure. Structure of bone is made of hydroxyaapatite crystals $\left(\mathrm{Ca}_{10}\left(\mathrm{PO}_{4}\right)_{6}(\mathrm{OH})_{2}\right.$ and other ions, an organic phase (osteoid) of collagen fibres and a ground substance formed by glycolproteins and proteoglycans. For optimal peak bone mass, nutritional $\mathrm{Ca}$ intake should be adequate and this effects the achievement of and modifies the rate of bone loss associated with ageing (8).

This study shows that, dietary calcium intake and meeting the percentage of recommended dietary requirements increased significantly in adolescent girls educated at frequent intervals for the six months to the study group. Nutritional education may result in a significant increase in BMD. Although, genetic, nutritional, environmental and lifestyle factors can also affect bone health, nutrition is an important modifiable factor in the maintenance of bone mass and in the prevention and treatment of osteoporosis $(12,13)$. Similar to our study, the findings of other studies conducted in USA indicate that dietary calcium intake was lower than the recommended amounts in adolescents $(14,15)$. Animal and vegetable protein sources rich in dietary calcium can meet the daily requirement, and epidemiologic studies suggest that lifetime high calcium intake is found to be associated with a reduced risk of fracture (12,16-18). Calcium retention significantly depends on the level of nutrient intake and bone mass increases when calcium intake is sufficient. In both females and males, the rate of maximal increase in whole body bone mineral content occurs during adolescence period. Hence, adequate dietary intake of calcium during adolescence is necessary to attain a peak bone mass that may lessen the risk of the fracture and the latter development of osteopenia (19). Most of the studies demonstrated that long-term levothyroxine treatment in children with congenital or acquired hypothyroidism did not affect BMD (20-25).On the other hand, a negative correlation between BMD and the duration of the therapy was shown by some other studies (25-28). Our study indicates that levothyroxine treatment does not have a negative effect on BMD in adolescent girls, similar to most of the studies.

In a study conducted by Salerno et al (21), children with congenital hypothyroidism who was taking calcium lower than the recommended amount (1300 mg/day) in the diet, had a similar BMD as adolescents given higher levels of calcium. But in our study, BMD increased significantly in adolescent girls with CLT who have taken higher levels of dietary calcium during follow up period. However, a positive correlation was only observed between the dietary intake of patients with CLT and BMD and BMD z-scores. This study suggested that dietary calcium had a positive effect on bone mineral density. The studies conducted in healthy, growing children showed that dietary calcium intake and the consumption of milk and dairy products were associated with increased bone mineral content (29-32). However, considering the fact that the study period was quite short, only six months, studies with longer follow-up is needed to define the positive benefits of nutrition education at frequent intervals on bone health.

In conclusion, in recent years, the importance and continuity of nutrition education for the prevention of many diseases and for the maintenance of health was emphasized in our country and the world (33-35). This study shows that continuous nutritional education for adolescent girls with CLT may have a positive impact on dietary calcium intake, and accordingly increased BMD.

\section{Study Limitations}

Evaluation of a larger group could be better for statistical analysis. Another point is that all of our patients had nutritional education for a calcium rich diet and thus we could not determine what would happen if they did not have such an education. A control group of adolescent girls with a diagnosis of CLT would help us reveal whether patients with a standart diet would have a decrease in BMD during thyroxine treatment and whether nutritional education would cause a significant difference. But for ethical reasons, we could not leave a group 
The Effect of Nutrition Education on Bone Health and Dietary Calcium Intake in Adolescent Girls with Chronic Lymphocytic Thyroiditis

without education. Because of better BMD in the study group correlating with healthy controls and correlating with their BMDs at the beginning of the study, we commented that nutritional education is helpful for better dietary Ca intake and an improvement in BMD.

Future Directions: Governments should support programmes for increasing dietary Ca intake in every age group, for both patients and healthy children.

Source of Funding: The study was supported by Hacettepe University Scientific Research Foundation Unit (Project No: 011D04401002).

Author's Contribution: Dr. Koc is the first author, wrote the paper and collected the data.

All authors have participated in the concept and design, analysis and interpretation of the data revising of the manuscript and approved the final version.

Blinded Information: This study was conducted in the period between September 2010 and June 2012 in Ankara Children's Hematology Oncology Training Hospital, Department of Pediatric Endocrinology on 31 adolescent girls, receiving levothyroxine therapy for the chronic lymphocytic thyroiditis, with the average age of $15.2 \pm 1.8(12.0-17.8)$ years.

All the laboratory measurements were conducted at the laboratory of Ankara Children's Health and Diseases Hematology Oncology Training and Research Hospital.

\section{REFERENCES}

1. Gorka J, Taylor-Gjevre RM, Arnason T. Metabolic and Clinical Consequences of Hyperthyroidism on Bone Density. Int. J. Endocrinology; doi:10.1155/2013/638727

2. Williams GR, Bassett JHD. Thyroid diseases and bone health. J Endocrinol Invest 2017.doi: 10.1007/s40618-017-0753-4.

3. Vestergaard P, Mosekilde L. Hyperthyroidism, bone mineral, and fracture risk--a metaanalysis. Thyroid : official journal of the American Thyroid Association 2003; 13: 585-93.

4. Blum MR, Bauer DC, Collet TH, Fink HA, Cappola AR, da Costa BR, Wirth CD, Peeters RP, Åsvold BO, den Elzen WP, et al. Subclinical thyroid dysfunction and fracture risk: a meta-analysis. JAMA 2015; 313: 2055-65.

5. AubertCE, Floriani C, Bauer DC, da Costa BR, Segna D, Blum MR, Collet TH, Fink HA, Cappola AR, Syrogiannouli L. et al. Thyroid Studies Collaboration. Thyroid Function Tests in the Reference Range and Fracture: Individual Participant Analysis of Prospective Cohorts. J Clin Endocrinol Metab 2017; 1: 102: 2719-2728.

6. Schneider R, Reiners C. The effect of Levothyroxine Therapy on Bone Mineral Density: A Systematic Review of the Literature. Exp Clin Endocrinol Diabetes 2003; 111: 455-470.

7. Numbenjapon N, Costin G, Pitukcheewanont P. Normalization of cortical bone density in children and adolescents with hyperthyroidism treated with antithyroid medication. Osteoporos Int 2012; 23: 2277-2282.

8. Flynn A. The role of dietary calcium on bone health. Proc Nutr Soc 2003; 62: 851-858.

9. Gökşen D, Darcan Ş, Coker M, Kose T. Bone Mineral Density of Healthy Turkish Children and Adolescents. J Clin Densitometry 2006; 9: 84-90.

10. Saka M, Koseler E, Metin S, Bilen S, Aslanyavrusu M, Ak F, Kiziltan G.Nutritional Status and anthropometric measurements of patients with multiple sclerosis. Saudi Med J 2012; 33: 160-166. 
The Effect of Nutrition Education on Bone Health and Dietary Calcium Intake in Adolescent Girls with Chronic Lymphocytic Thyroiditis

11. The Ministry of Health of Turkey, General Directorate of Primary Health Care, Food Safety Department Community Nutrition Division. Dietary Guidelines for Turkey. Ed (in English) Ankara, Turkey, 2006; 57-65.

12. Coşkun T. Nutrition and Bone Health. J Pediatr Sci 2008; 4: 6-20.

13. Bronner YI, Hawkins AS, Holt ML, Hossain MB, Rowel RH, Sydnor KL, Divers SP. Models for Nutrition Education to Increase Consumption of Calcium and Dairy Products among African Americans. J. Nutr 2006; 136: 1103-1106.

14. Moore LL, Bradlee ML, Gao D, Singer MR. Effects of Averrage Childhood Dairy Intake on Adolescent. Bone Health 2008; 153: 667-673.

15. Storey ML, Forshee RA, Anderson PA. Associations of Adequate Intake of Calcium with Diet, Beverage Consumption, and Demographic Characteristics among Children and Adolescents. J Am Coll Nutr 2004; 23: 18-33.

16. Gao X, Wilde PE, Lichtenstein AH, Tucker KL. Meeting Adequate Intake for Dietary Calcium without Dairy Foods in Adolescents Aged 9 to 18 Years (National Health and Nutrition Examination Survey 2001-2002). J Am Diet Assoc 2006; 106: 1759-1765.

17. Peters BSE, Martini LA. Nutritional aspects of the prevention and treatment of osteoporosis. Arg Bras Endocrinol Metab 2010; 54: 179-185.

18. Caroli A, Poli A, Ricotta D,Banfi G, Cocchi D. Invated review: Dairy intake and bone health: a view-point from the status of art. J Dairy Sci 2011; 94: 5249-5262.

19. Greer FR, Krebs NF, Optimizing bone health and calcium intakes of infants, children, and adolescents. Pediatrics 2006;117: 578-585.

20. Salama HM, El-Dayem SA, Yousef H, Fawzy A, Abou-Ismail L, El-Lebedy D. The effects of L-thyroxin replacement therapy on bone minerals and body composition in hypothyroid children. Arch Med Sci 2010; 30: $407-13$

21. Salerno M, Lettiero T, del Puante AE. Guardasole V, Mattiacci DM, Saldamarco L, Capalbo D, Lucariello A, Saccà L, Cittadini A. Effect of long term L-thyroxine treatment on bone mineral density in young adults with congenital hypothyroidism. Eur J Endocrinology 2004; 151: 689-694.

22. Leger J, Ruiz JC, Guibourdenche J, Kindermans C, Garabedian M, Czernichow P. Bone mineral density and metabolism in children with congenital hypothyroidism after prolonged L-thyroxin therapy. Acta Paediatr 1997; 86: 704-710.

23. Tumer L, Hasanoglu A, Cinaz P, Bideci A. Bone mineral density and metabolism in children treated with L-thyroxine. J Pediatr Endocrinol Metab 1999; 12: 519-23.

24. Kooh S W, Brnjac L, Ehrlich RM, Qureshi R, Krishnan S. Bone mass in children with congenital hypothyroidism treated with thyroxine since birth. J Pediatr Endocrinol Metab 1996; 9: 59-62.

25. Saggese G, Bertelloni S, Baroncelli GI, Costa S, Ceccarelli C. Bone mineral density in adolescent females treated with L-thyroxine: a longitudinal study. Eur J Pediatr 1996; 155: 452-7.

26. Affinito P, Sorrentino C, Farace MJ,Carlo C, Moccia G, Canciello P, Palomba P, Nappi C. Effects of thyroxine therapy on bone metabolism in postmenapausal women with hypothyroidism. Acta Obstet Gynecol Scand 1996; 75: 843-848.

American Research Journal of Pediatrics

Page 8 
The Effect of Nutrition Education on Bone Health and Dietary Calcium Intake in Adolescent Girls with Chronic Lymphocytic Thyroiditis

27. Ribot C, Tremollieres F, Pouilles JM, Louvet JP. Bone mineral density and thyroid hormone therapy. Clin Endocrinol (Oxf) 1990; 33: 143-153.

28. Hadji P, Hars O, Sturm G, Bauer T, Emons G, Schulz KD. The effect of long-term, non-suppressive levothyroxine treatment on quantitative ultrasonometry of bone in women. Eur J Endocrinol 2000; 142: 445-450.

29. Burrows M, Boxter-Jones A, Mirwald R, Macdonald H, MacKay H. Bone Mineral Accrual Across Growth in a Mixed-Ethnic Group of Children: Are Asian Children Disadvantaged from on Early Age? Calcif Tissue Int 2009; 84: 366-378.

30. Abreu S, Santos R, Noreira C, Santos PC, Vale S, Soares-Miranda L, Mota J, Moreira P. Milk intake is inversely related to body mass index and body fat in girls. Eur J Pediatr 2012; 171: 1467-1474.

31. Huncharek M, Muscat J, Kupelnick B. Impact of dairy products and dietary calcium on bone-mineral content in children: Results of meta-analysis. Bone 2008; 43: 312-321.

32. Matkovic V, Landoll JD. Badenhop-Stevens NE, HaEY Crncevic-Orlic Z, Li B, Goel P. Nutrition Influences Skeletal Development from Childhood to Adulthood: a Study of Hip, Spine, and Forearm in Adolescent Females. J Nutr 2004; 134: 701-705.

33. Ratner G R, Durán A S, Garrido L MJ, Balmaceda H S, Jadue H L, Atalah S E. Impact of an intervention on diet and physical activity on obesity prevalence in school children. Nutr Hosp 2013; 28: 1508-1514.

34. Sands D, Mielus M, Umławska W, Lipowicz A, Oralewska B, Walkowiak J. Dietary Pattern and its Relationship Between Bone Mineral Density in Girls and Boys with Cystic Fibrosis - preliminary report. Dev Period Med 2015;19: 105-113.

35. Naghashpour M, Shakerinejad G, Lourizadeh MR, Hajinajaf S, Jarvandi F. Nutrition education based on health belief model improves dietary calcium intake among female students of junior high schools. J Health Popul Nutr 2014;32: 420-429.

Citation: Nevra Koç, Ph.D., Emine Akal Yıldız, Ph.D., İhsan Esen, MD, Gülhan Samur, Ph.D., Seyit Ahmet Uçaktürk, MD, Mehmet Gündüz, MD, "The Effect of Nutrition Education on Bone Health and Dietary Calcium Intake in Adolescent Girls with Chronic Lymphocytic Thyroiditis". American Research Journal of Pediatrics. 2018; 2(1): 1-9.

Copyright @ 2018 Nevra Koç, Ph.D., Emine Akal Yıldız, Ph.D., İhsan Esen, MD, Gülhan Samur, Ph.D., Seyit Ahmet Uçaktürk, MD, Mehmet Gündüz, MD. This is an open access article distributed under the Creative Commons Attribution License, which permits unrestricted use, distribution, and reproduction in any medium, provided the original work is properly cited. 